\title{
Percent Recovered Infinity Predicted Normalized by Body Mass Index
}

National Cancer Institute

\section{Source}

National Cancer Institute. Percent Recovered Infinity Predicted Normalized by Body

Mass Index. NCI Thesaurus. Code C112392.

The percentage of the recovered administered dose extrapolated to infinity, calculated using the predicted value of the last non-zero concentration, divided by the body mass index. 